\title{
Essentialist Beliefs and Social Distance towards Gay Men and Lesbian Women: A Latent Profile Analysis
}

\author{
Elena R. Agadullina \\ School of Psychology \\ National Research University Higher School of Economics \\ Moscow, Russia \\ Andrey V. Lovakov \\ Center for Institutional Studies \\ National Research University Higher School of Economics \\ Moscow, Russia \\ Natalia G. Malysheva \\ Faculty of Psychology \\ Lomonosov Moscow State University \\ Moscow, Russia \\ In press \\ Psychology \& Sexuality \\ DOI: 10.1080/19419899.2018.1488764
}

Correspondence should be addressed to Elena Agadullina, eagadullina@hse.ru 


\begin{abstract}
Psychological essentialism is the layperson's belief that social categories are natural and entitative. Studies have shown that essentialist beliefs are strongly connected with different types of prejudice. Previous research into essentialist beliefs predominantly used a variable-centered approach to investigate the relationship between essentialist beliefs and prejudice. Extending this research, we used a person-centered approach to explore the relationship between different essentialist beliefs related to sexual orientation and gender (naturalness, homogeneity, discreteness and informativeness). The study involved 282 (sample 1) and 194 (sample 2) respondents from Russia with different sexual orientations. Using latent profile analysis, we identified three distinct essentialist belief profiles, which are the same for both our target groups, gay men and lesbian women. We examined the relationships between belonging to essentialist belief profiles and social distance towards gay men and lesbian women. We found individuals from various profiles differed in levels of gender identification and rightwing authoritarianism. Individuals with relatively low levels of naturalness beliefs and high levels of essentialist beliefs about the social and psychological differences between gender groups and between heterosexuals and non-heterosexuals demonstrated greater social distance towards gay men and lesbian women compared to respondents with lower essentialist beliefs in the differences between groups.
\end{abstract}

Keywords: essentialism, beliefs, gender, sexual orientation, social distance, latent profile analysis 


\section{Introduction}

Despite increasingly egalitarian attitudes towards non-heterosexuals in many European countries and the USA, homonegativity is still widespread in some post-Soviet countries, especially in Russia (O'Dwyer, 2013). According to the Levada Centre (a non-governmental sociological service), $37 \%$ of Russians perceive homosexuality as a disease to be treated, $26 \%$ think of it as a result of poor upbringing and debauchery, and only $11 \%$ consider it an inborn type of human sexuality (Pipiya, 2015). In general, Russians believe that gay men and lesbian women are very different from heterosexuals, that they 'chose to be this way', and that homosexuality is a physical, moral and religious deviation (Gulevich, Osin, Isaenko, \& Brainis, 2016, 2017). In 2013, homonegativity in Russia was transformed into an external legal social norm by laws that aimed to prohibit non-traditional sexual relations among minors. The Levada Centre estimated that $77 \%$ of Russians favor these so-called 'anti-gay' laws (Pipiya, 2015) and according to the Human Rights Watch report these laws increased the spread of homophobic violence in Russia (Human Rights Watch, 2014). Soboleva and Bakhmetjev (2015) showed that lesbian, gay, bisexual and transgender (LGBT) people in Russia feel that their basic human rights are violated and in order to maintain their physical and psychological well-being they have to become 'invisible' in society. In fact, since 2013 individuals cannot describe a non-heterosexual relationship in a positive context, teachers cannot talk about the nature of sexual orientation and nonheterosexuals cannot 'come out' in public, because all of these might be considered as promoting of non-traditional values and sexual relations. 
Heteronormativity is the idea that heterosexuality is the only norm and the 'essential' type of human sexual identity, in contrast to other types (Schilt \& Westbrook, 2009). This view helps to maintain the special social hierarchy (Jost, Banaji, \& Nosek, 2004; Williams \& Eberhardt, 2008) and naturalizes the institution of heterosexuality (Ingraham, 1994). It is supported not only in political and social contexts, but also by essentialist thinking. Essentialist beliefs are the layperson's acceptance that members of social categories have fixed, underlying and identitydetermining essences that make them who they are. Haslam, Rothschild and Ernst (2000) showed that essentialist beliefs could be described through two factors: "natural kind' and 'entitativity'. The first factor includes beliefs that a social category has a deep-rooted biological basis (naturalness belief). The second factor includes beliefs about an underlying, inherent nature of a social category (informativeness belief), the homogeneity of group members (homogeneity belief), and representation that the category does not include members from other categories (discreteness belief). Essentialist beliefs emphasize the boundaries between groups and reinforce the categorization of 'we and they'. As a result, essentialist thinking leads to a desire for heterosexual people to be separate and socially distanced from non-heterosexual people. Social distance is the level of physical and social intimacy that heterosexual individuals are willing to tolerate from non-heterosexuals, and their willingness to interact with non-heterosexuals. Social distance is a good way to measure the homonegativity in a society where it is a pattern of everyday behavior for a large number of people (as in Russia), because it reflects real differences in the economic, 
political and social status of heterosexuals and non-heterosexuals. Homonegativity as the subtle beliefs that the equal rights between heterosexuals and homosexual individuals are illegitimate and unnecessary, discrimination towards homosexuals no longer exists, and homosexual individuals are responsible for their own marginalization in society (Morrison \& Morrison, 2003) is fixed by the federal laws, which allow people at the legal level to request exclusion of non-heterosexuals from social life.

\section{Essentialist beliefs related to sexual orientation}

Haslam and Levy (2006) described different essentialist beliefs about sexual orientation and demonstrated that they are connected with negative attitudes in various ways. The belief that homosexuals are 'born this way' (naturalness belief) is not significantly associated with negative attitudes (Haslam \& Levy, 2006; Hegarty, 2002; Hubbard \& de Visser, 2015; Jayaratne et al., 2006). At the same time, essentialist beliefs emphasizing deep social or psychological differences between heterosexuals and non-heterosexuals predict negative attitudes toward non-heterosexuals (Arseneau, Grzanka, Miles, \& Fassinger, 2013; Grzanka, Zeiders, \& Miles, 2016; Haslam \& Levy, 2006; Rios, 2013). In other words, when people believe that an individual can be either homosexual or heterosexual (discreteness belief), that homosexuality tells a lot about personality (informativeness belief), and that all homosexuals share common social and psychological attributes (homogeneity belief), they are more prejudiced.

Lytle, Dyar, Levy, and London (2017) showed that attitudes toward gay men and lesbian women are positively related to social distance (readiness of intergroup 
contact), and that this relationship is mediated by essentialist beliefs related to group boundaries. These boundaries can be biological, such as when people believe in the naturalness of sexual orientation, or social, such as when people believe in strong differences between heterosexuals and non-heterosexuals. In general, people who believe in boundaries between groups express more negative attitudes towards gay men and lesbian women and strongly keep their social distance (Roberts, Ho, Rhodes, \& Gelman, 2017).

\section{Essentialist beliefs related to gender}

Previous studies have shown that gender is a highly essentialized category (Bastian \& Haslam, 2006; Prentice \& Miller, 2007; Smiler, Gelman, Schomerus, Matschinger, \& Angermeyer, 2014). Gender essentialism is the belief that the natures of women and men are inborn and fixed (Morton, Postmes, Haslam, \& Hornsey, 2009), and that gender roles and stereotypes are the natural result of biological differences between males and females (Prentice \& Miller, 2006). People with genderessentialist beliefs perceive, for instance, that women (as a gender group) are similar to each other (homogeneity belief) and distinct from men, because an individual must be either a man or a woman (discreteness belief). Moreover, they believe that if someone is a woman, this fact says a lot about her personality and behavior (informativeness belief). In other words, the fact of belonging to a certain gender group is enough to justify the stereotypes and draw conclusions about the person as a whole. Genderessentialist beliefs are one part of a gender belief system (Kite \& Deaux, 1987). This system includes stereotypes about gender roles (e.g., women should be a housewife, 
while men should to make a career), masculine and feminine traits (e.g., women should be warm, while men should be aggressive), physical attributes and behaviors (e.g., women should love children, men should act like a leader). People with essentialist thinking endorse gender stereotypes more strongly and avoid information that might challenge those stereotypes (Levy, Chiu, \& Hong, 2006); as a result, they support the immutability of a gender belief system.

To the layperson, gender stereotypes describe not only expectations about manners of dress, behavior and professional status, but also differences in sexual behaviors (Nürnberger, Nerb, Schmitz, Keller, \& Sütterlin, 2015). Specifically, people believe that men must be masculine and sexually prefer women, whereas women must be feminine and sexually prefer men (see for example, McCutcheon \& Morrison, 2015). Reyna, Wetherell, Yantis, and Brandt (2014) found that the opinion that nonheterosexuals violate certain core values and traditional gender roles (for example, regarding sexual preference) could explain the prejudice towards non-heterosexuals. However, the evaluations of men and women violating gender norms differ, as men are blamed more and punished for behavior deviating from gender norms than are women (Phoenix, Frosh, \& Pattman, 2003). This is because gender norm boundaries for men are more rigid than those for women (Falomir-Pichastor \& Hegarty, 2014), and because gay and straight men are viewed as more dissimilar from one another than are lesbian and straight women (Hegarty \& Pratto, 2004). Muraco (2005) showed that, based on normative beliefs about sex, heterosexual college students keep more social distance from their gay or lesbian friends than from each other. Roberts, Ho, Rhodes, 
and Gelman (2017) found that people who have greater gender essentialist beliefs show more support for gender-based segregation in education and lower support for initiatives or legislation aimed at supporting transgender persons.

As a result, we suggest there are at least three different co-existing essentialist beliefs related to sexual orientation and gender that may be sources of increased desire for social distancing from non-heterosexuals: belief in the naturalness of sexual orientation, belief in strong social and psychological differences between heterosexuals and non-heterosexuals, and belief in gender differences between men and women.

\section{The current study}

Following the theoretical approach of Haslam, Rothschild, and Ernst (2000; 2002), who allocated biological and psychological components to essentialist beliefs, and the empirical evidence that these components are connected with prejudice towards non-heterosexuals predominantly in different ways (Brickman, 2009), we identified three types of essentialist beliefs that could be considered as sources of social distance. The first type includes a belief in the naturalness of sexual orientation (biological basis). The second comprises the essentialist beliefs emphasizing the deeply social or psychological differences between gay men/lesbian women and heterosexuals (discreteness, informativeness and homogeneity). The third type contains the essentialist beliefs related to gender stereotypes and perception of gender as a binary category (discreteness, informativeness, homogeneity). 
Grzanka and colleagues (2016) showed that different beliefs about sexual orientation might co-exist in lay representations. In particular, there are two separate groups of people, who differ in their perception of the discreteness, homogeneity, naturalness and informativeness of sexual orientation. The first group includes respondents who report relatively high levels of all beliefs (discreteness, homogeneity, informativeness and naturalness), while the second group comprises respondents who demonstrate a high level of naturalness belief but low levels of the other beliefs. We suggest that an essentialist belief about gender could be an additional source of negative attitudes and that this belief might co-exist with the essentialist beliefs related to sexual orientation. This study's first objective was to identify groups of individuals with similar combinations (profiles) of essentialist beliefs about sexual orientation and gender. To achieve the first objective, we applied a person-centered approach (as opposed to a variable-centered approach) to the study of lay beliefs about sexual orientation and gender. Previous studies in the field were predominantly based on a variable-centered approach. They examined the independent relationships of essentialist beliefs about sexual orientation and gender with attitudes towards nonheterosexuals. This approach has some limitations; it does not take into account the fact that various beliefs (even contradictory ones) might co-exist in an individual mind and that different configurations of beliefs can exist across individuals. These limitations can be overcome by the person-centered approach, which considers how different variables group within individuals and takes into account the possibility of the existence in the sample of subgroups that differ in the features of the combination 
of essentialist beliefs, making it possible to divide individuals into relatively homogeneous groups that are qualitatively and quantitatively different from each other (Marsh, Lüdtke, Trautwein, \& Morin, 2009; Morin, Morizot, Boudrias, \& Madore, 2011). A person-centered approach allows us create a more holistic view of the essentialist beliefs related to sexual orientation and gender co-existence and the complex relationships between these essentialist beliefs and other variables. Studies have shown that identification with gender group (Falomir-Pichastor \& Mugny, 2009; Zagefka, Nigbur, Gonzalez, \& Tip, 2013), social dominance orientation (SDO) (Keller, 2005) and right-wing authoritarianism (RWA) (Haslam \& Levy, 2006; Rowatt, LaBouff, Johnson, Froese, \& Tsang, 2009) are the main covariates of essentialist beliefs. In particular, essentialist beliefs are strongly associated with social dominance, authoritarianism, and group identification. As a result, it can be expected that individuals with different essentialist belief profiles will also differ in SDO, RWA and identification.

The first research question was formulated in the following way:

Research Question 1: Which distinctive groups of individuals with essentialist beliefs about sexual orientation and gender exist in the case of the perception of gay men and lesbian women? How do individuals from these groups differ in their level of RWA, SDO, and gender identification?

The study's second objective is to explore the differences between groups of individuals with different combinations (profiles) of essentialist beliefs about sexual orientation and gender in their desire to keep a social distance from gay men and 
lesbian women. As studies show, essentialist beliefs emphasize the similarities within and differences between groups (accentuating the biological, social and psychological differences between men and women or between gay men/lesbian women and heterosexuals), thereby making the boundaries between groups more visible. Consequently, these beliefs could lead to an increase in the social distance between groups that, in turn, could lead to support for discriminatory laws and initiatives (Roberts et al., 2017). At the same time, individuals with different essentialist belief profiles might in varying degrees emphasize the boundaries between groups and this could lead to differences in social distance. Based on this assumption, we formulated a second research question.

Research Question 2: Do individuals with different combinations (profiles) of essentialist beliefs about sexual orientation and gender differ in their levels of social distance from gay men and lesbian women?

\section{Method}

\section{Participants}

Data were collected as part of a large survey about the perception of sexual orientation in Russia. The survey had a total of 897 respondents. However, only some of respondents were asked questions that are relevant for the current study. As a result, we obtained two partly intersecting samples. A group of 282 participants evaluated gay men and gender as a social category. This part of the sample consisted of $16.3 \%$ males $(n=46)$ and $83.7 \%$ females $(n=236)$, aged between 18 and 48 years, $M_{\text {age }}=20.3$, 
$S D_{\text {age }}=4.1$. A group of 194 participants evaluated lesbian women and gender as a social category. This part of the sample included $18.6 \%$ males $(n=36)$ and $81.4 \%$ females $(n=158)$, also aged between 18 and 48 years, $\mathrm{M}_{\text {age }}=20.7, S D_{\text {age }}=4.3$. Some participants evaluated both the gay men and lesbian groups. Most studies about essentialist beliefs related to sexual orientation have been conducted on the dominant population (heterosexuals). As a result, most of their findings are representative only for heterosexuals. To overcome this limitation in the current study, we tried to include in the sample individuals with different sexual orientations. The full demographics are presented in Table 1.

Table 1. Demographics

\begin{tabular}{lrccrr}
\hline Sample 1 $(n=282)$ & $\boldsymbol{n}$ & $\mathbf{\%}$ & Sample 2 $(n=194)$ & $\boldsymbol{n}$ & $\mathbf{\%}$ \\
\hline Age $\left(M_{\text {age }}=20.3\right.$, & & & Age $\left(M_{\text {age }}=20.7\right.$, & & \\
$\left.S D_{\text {age }}=4.1\right)$ & & & $\left.S D_{\text {age }}=4.3\right)$ & & \\
$18-20$ & 191 & 67.7 & $18-20$ & 124 & 63.9 \\
$21-30$ & 81 & 28.8 & $21-30$ & 62 & 32.0 \\
$31-40$ & 6 & 2.1 & $31-40$ & 5 & 2.6 \\
$41-50$ & 2 & 0.7 & $41-50$ & 3 & 1.5 \\
missing & 2 & 0.7 & missing & 0 & 0.0 \\
Gender & & & Gender & \\
Women & 236 & 83.7 & Women & 158 & 81.4 \\
Men & 46 & 16.3 & Men & 36 & 18.6 \\
Sexual orientation & & & Sexual orientation & & \\
Heterosexual & 101 & 35.8 & Heterosexual & 76 & 39.2 \\
$\quad$ women & 82 & 81.2 & women & 63 & 84.2 \\
$\quad$ men & 19 & 18.8 & men & 12 & 15.8 \\
Homosexual & 20 & 7.1 & Homosexual & 14 & 7.2 \\
$\quad$ women & 10 & 50.0 & women & 6 & 42.9 \\
$\quad$ men & 10 & 50.0 & men & 8 & 57.1 \\
Bisexual & 89 & 31.6 & Bisexual & 58 & 29.9 \\
$\quad$ women & 79 & 88.8 & women & 48 & 82.7 \\
men & 10 & 11.2 & men & 10 & 17.2 \\
Other & 72 & 25.5 & Other & 46 & 23.7 \\
$\quad$ women & 65 & 90.3 & women & 40 & 87.0 \\
$\quad$ men & 7 & 9.7 & men & 6 & 13.0 \\
\hline & & & &
\end{tabular}

\footnotetext{
${ }^{1}$ The category 'other' included the respondents with another non-heterosexual identity (besides homosexuals and bisexuals)
} 


\section{Measures}

\section{Essentialist beliefs scale}

Based on the research of Haslam and colleagues (2000; 2002) a seven-item scale of essentialist beliefs was developed in Russian. Items related to the discreteness, homogeneity and informativeness beliefs were selected from previous works and translated into Russian by the authors and then back-translated by a bilingual assistant. The psychometric properties of the scale were tested on independent samples. The one-factor model showed good fit. Depending on the target group CFI was .981 (for gay men) and .953 (for lesbian women), TLI was .972 (for gay men) and .929 (for lesbian women), RMSEA was .038 (for gay men) and .063 (for lesbian women). The results of measurement invariance analyses showed that the measure exhibits configural, metric and scalar invariance (Agadullina \& Chumakova, 2017). The final scale included seven items about discreteness (e.g., 'Gay men is a category with clear boundaries: a man is either gay or he isn't' / 'Gender is a category with clear boundaries: a person is either a man or a woman'), homogeneity (e.g., 'Gay men are very similar to one another' / 'People with one gender are very similar to one another'), and the informativeness of the category (e.g., 'Knowing that someone is gay tells you a lot about his personality' / 'Knowing that someone belongs to a certain gender group tells you a lot about his personality'). Respondents filled in the scales for gay men $(\alpha=.81,95 \%$ CI [.78-.83]), lesbian women $(\alpha=.80,95 \%$ CI [.78-.83]) and $\operatorname{gender}^{2}(\alpha=.79,95 \%$ CI [.77-.82]) separately. All items were rated on a 7-point 
Likert scale $(1=$ strongly disagree, $7=$ strongly agree $)$. The mean scores for each group were calculated; the higher scores indicated the greater essentialist beliefs.

\section{Naturalness beliefs about sexual orientation}

Two items were adapted from Horvath and Ryan (2003) to measure belief in the naturalness of sexual orientation ('People choose to be gay men' (reverse), 'Gay men were born this way'/ 'People choose to be lesbian women' (reverse), 'Lesbian women were born this way'). The equivalence of the translation was checked by a backtranslation procedure that was made by the bilingual assistant. Responses were made on a 7-point Likert scale $(1=$ strongly disagree, $7=$ strongly agree $)$. The reliability of the scales (Spearman's rank correlation) was moderate (gay men $r=.48,95 \%$ CI [.37$.59]$; lesbian women $r=.50,95 \%$ CI [.37-.63]). The mean scores for each group were calculated; the higher scores indicated the greater naturalness beliefs.

\section{Social distance}

Participants completed a measure of desire for distance from gay men/lesbian women (adapted from Esses and Dovidio (2002)). Participants were asked how close they would want to be to gay men/lesbian women ( 1 - to be related to a gay man/lesbian; 2 - to share an apartment with a gay man/lesbian; 3 - to be friends with gay men/lesbian women; 4 - to work or study in the same organization as gay men/lesbian women; 5 - to live with gay men/lesbian women in the same city; 6 - to live with gay men/lesbian women in the same country; 7 - or not wanting to live in the same country as gay men/lesbian women). Participants chose one item (from seven) 
that best describes their desired level of proximity with gay men and lesbian women. The higher score indicated the greater social distance.

\section{Gender identification}

In-group identification with gender group was measured by the Russian version of the (Leach et al., 2008) measure of in-group identification, which included 14 items (e.g., 'I feel solidarity with men/women', 'Men/women are very similar to each other', etc.). Responses were made on a 7 -point Likert scale $(1=$ absolutely disagree, $7=$ absolutely agree). The mean score was calculated; the higher scores indicated the greater gender identification. The Russian version of the scale has adequate psychometric properties (Lovakov, Agadullina, \& Osin, 2015). In the present study the Cronbach's alpha is .90 (95\% CI [.88-.91]).

\section{Social dominance orientation (SDO)}

The Russian adaptation (Gulevich, 2017) of the 16-item SDO scale (Pratto, Sidanius, Stallworth, \& Malle, 1994) was used (e.g., 'Some groups of people are just more worthy than others', 'It would be good if all groups could be equal', etc.). All items were rated on the 7 -point Likert scale $(1=$ strongly disagree, $7=$ strongly agree). The mean score was calculated; the higher scores indicated the greater SDO. In the present study the Cronbach's alpha is .97 (95\% CI [.96-.97]).

Right-wing authoritarianism (RWA)

Willingness to submit to authorities was measured by a Russian version (Gulevich, 2017) of the 22-item RWA scale (Altemeyer, 2006) (e.g., 'The only way our country can get through the crisis ahead is to get back to our traditional values, put 
some tough leaders in power, and silence the troublemakers spreading bad ideas', 'To lead the best, most meaningful life, one must belong to the one, true religion', etc.). Responses were made on a 7 -point Likert scale $(1=$ absolutely disagree, $7=$ absolutely agree). The mean score was calculated; the higher scores indicated the greater authoritarian attitudes. In the present study the Cronbach's alpha is .93 (95\% CI [.92-.94]).

\section{Procedure}

An advertisement about taking part in a study of perceptions of various social groups was distributed in various LGBT and heterosexual communities on the most popular and widespread social network in Russia, Vkontakte (the Russian equivalent of Facebook). The advertisement explained that participation in the research was voluntary, anonymous and free of charge and that participants may quit at any time. Individuals wishing to participate used a link to the survey's web address. Respondents were randomly assigned to rate three out of four groups: gender (as a social category), homosexuals (as a whole group), gay men and lesbian women. Items relating to each group were administered on a separate page, and the order of the target group was randomized. All data were collected through a Virtualexs system (a specialized system for the collection of empirical data). The survey had a total of 897 participants. The respondents who evaluated only homosexuals, gay men or lesbian women (but not gender), were not included in the samples for this study. Although 
only people aged 18 and above were invited to participate in the survey, 29 people under that age also completed questionnaires. They were removed from the sample.

\section{Data Analysis}

The aim of this study was to identify groups of individuals with similar combinations (profiles) of essentialist beliefs about sexual orientation and gender. Such groups can be identified by randomly dividing the sample into high and low groups by mean or median, however this method has a serious limitation associated with the risk of identifying artificial groups which do not exist in reality. More reliable ways to identify specific groups or profiles include cluster analysis and latent profile analysis (LPA). We used LPA because it has several advantages over cluster analysis (Magidson \& Vermunt, 2002). LPA is a mixture model that aims to identify and describe subgroups of participants differing in their configuration on the sets of indicators. LPA is based on the assumption that the correlations between the indicators may be explained by the existence of a categorical latent variable representing qualitatively and quantitatively distinct latent profiles of individuals within the sample (Morin et al., 2011). LPA also allows for specifying alternative models with a different number of subgroups (latent profile) and for comparing them based on fit statistics. There are several statistical indicators to determine the optimal number of latent profiles. However, simulation studies show that the Bayesian information criterion (BIC; Schwarz, 1978) and the bootstrapped likelihood ratio test (BLRT; McLachlan \& Peel, 2000) are the most effective ones (Nylund, Asparouhov, \& Muthén, 2007). A 
lower BIC value indicates a better-fitting model; the $p$-value generated for the BLRT indicates whether the solution with $k$ profiles $(p<.05)$ or $k-1$ profiles $(p>.05)$ fits better. LPA was conducted separately for essentialist beliefs regarding gay men and lesbian women. In each case, the profiles included the three beliefs that might be a source of negative attitudes towards gay men or lesbian women (naturalness beliefs about sexual orientation, essentialist beliefs related to sexual orientation (gay men or lesbian women) and essentialist beliefs related to gender). The LPA was conducted using the Mplus 7.4 robust maximum likelihood estimator. LPA models, including one to five latent profiles, were consistently estimated. In all models, the means of the profile indicators were freely estimated for all profiles. To avoid converging on a local solution, the models were estimated with 3,000 random sets of start values, each of which was allowed 200 iterations, and the 200 best were retained for final stage optimization. The profiles from the ultimate solution were compared on the basis of demographic covariates (age, gender and sexual orientation), gender identification, social dominance orientation, and right-wing authoritarianism. A comparison was carried out using the Mplus AUXILIARY (e) function, which tests the equality of means across profiles.

\section{Results}

Descriptive Statistics and Preliminary Analysis

Table 2 presents the descriptive statistics and correlations among the main study variables. Overall, SDO and RWA associated with social distance toward gay men than 
lesbian women. The essentialist beliefs related to gender and identification with gender group is linked to the social distance toward lesbian women only.

\section{Latent profile analysis}

The fit indices for the LPA models containing from one to five profiles are shown in Table 3. The models with three latent profiles demonstrated the lowest BIC value both in the case of gay men (2273) and in that of lesbian women (1549). BLRT showed that the solution with three latent profiles was better than the solution with four latent profiles in the case of lesbian women, but in the case of gay men the solutions with four and five latent profiles were better. However, the smallest profile sizes in the four- and five-profile solutions were only six (2.12\%) and eight (2.84\%) individuals, respectively. Subgroups of these sizes are very small, may give meaningless estimation of the mean levels of indicators, and should not be considered reliable representations of the subgroups in the general population. Therefore, the three-profile solution was considered the best overall fit to the data in both cases. These models showed acceptable classification probabilities for the most likely latent class membership, which ranged from .826 to .881 for gay men and from .796 to .933 for lesbian women. Figure 1 graphically illustrates the results from the retained threeprofile solution. The exact mean values for the essentialist beliefs in each profile are presented in Table 4. 
Table 2. Mean, Standard Deviation, Internal Consistency and Zero-Order Correlations for Variable in Sample 1 (Gay men: above the diagonal) and Sample 2 (Lesbian women: below the diagonal)

\begin{tabular}{|c|c|c|c|c|c|c|c|c|c|c|c|c|c|}
\hline & \multicolumn{3}{|c|}{ Gay men } & \multicolumn{3}{|c|}{ Lesbian women } & \multirow[b]{2}{*}{1} & \multirow[b]{2}{*}{2} & \multirow[b]{2}{*}{3} & \multirow[b]{2}{*}{4} & \multirow[b]{2}{*}{5} & \multirow[b]{2}{*}{6} & \multirow[b]{2}{*}{7} \\
\hline & $M$ & $S D$ & $\alpha$ & $M$ & $S D$ & $\alpha$ & & & & & & & \\
\hline 1. RWA & 2.53 & 1.44 & .93 & 2.57 & 1.42 & .93 & - & $.543 * *$ & .092 & $.586 * *$ & $.446^{* *}$ & $.327 * *$ & $.309 * *$ \\
\hline 2. SDO & 2.73 & 1.06 & .89 & 2.69 & 1.02 & .89 & $.543 * *$ & - & .004 & $.483 * *$ & $.304 * *$ & $.223 * *$ & $.241 * *$ \\
\hline 3. Identification & 4.22 & 1.01 & .89 & 4.26 & 1.06 & .90 & .125 & .062 & - & .021 & $.298 * *$ & $.431 * *$ & $.186^{* *}$ \\
\hline 4. Social Distance & 1.84 & 1.69 & - & 1.49 & 1.05 & - & $.420 * *$ & $.277 * *$ & $.229 * *$ & - & $.244 * *$ & .086 & $.146 *$ \\
\hline 5. EB belief gay men / lesbian women & 2.47 & 0.99 & .81 & 2.46 & 1.01 & .80 & $.478 * *$ & $.308 * *$ & $.294 * *$ & $.400 * *$ & - & $.639 * *$ & $.301 * *$ \\
\hline 5. EB gender & 2.61 & 0.94 & .80 & 2.63 & 0.98 & .81 & $.390 * *$ & $.218 * *$ & $.435^{* *}$ & $.341 * *$ & $.643 * *$ & - & $.338 * *$ \\
\hline $\begin{array}{l}\text { 7. Naturalness belief gay men / lesbian } \\
\text { women }\end{array}$ & 3.32 & 1.70 & $.48^{\mathrm{a}}$ & 3.37 & 1.74 & $.50^{\mathrm{a}}$ & $.310 * *$ & $.277 * *$ & $.282 * *$ & $.223 * *$ & $.369 * *$ & $.338 * *$ & - \\
\hline
\end{tabular}

Note: RWA - Right-wing authoritarianism, SDO - Social dominance orientation, EB - essentialist beliefs $* p<.05 ; * * p<.01$

a - Spearman correlation for two items 
Table 3. Fit indices for different models from the latent profiles analyses

\begin{tabular}{lccl}
\hline Model & BIC & BLRT $(\boldsymbol{p})$ & Profiles' size \\
\hline Gay men & & & \\
1 Profile & 2432 & - & 282 \\
2 Profiles & 2287 & $<.0001$ & $71 / 211$ \\
3 Profiles & 2273 & $<.0001$ & $122 / 44 / 116$ \\
4 Profiles & 2274 & $<.0001$ & $112 / 6 / 121 / 43$ \\
5 Profiles & 2274 & $<.0001$ & $69 / 83 / 72 / 50 / 8$ \\
\hline Lesbian women & & & \\
1 Profile & 1680 & - & 194 \\
2 Profiles & 1550 & $<.0001$ & $63 / 131$ \\
3 Profiles & 1549 & $<.0001$ & $104 / 30 / 60$ \\
4 Profiles & 1559 & .1400 & $44 / 46 / 80 / 24$ \\
5 Profiles & 1566 & .0600 & $90 / 40 / 35 / 6 / 23$ \\
\hline
\end{tabular}

Note: BIC - Bayesian information criterion; BLRT $(p)=$ Bootstrapped likelihood ratio test ( $p$-value).

Table 4. Mean levels of the essentialist beliefs related to gender and sexual orientation, and beliefs in naturalness

\section{Profile 1 Profile 2 $\quad$ Profile $3 \quad$ Summary of} significance tests

\begin{tabular}{lrrrr}
\hline Gay men & & & \\
EB Gender & -0.783 & 1.535 & 0.242 & $1<3<2$ \\
EB Gay men & -0.824 & 1.551 & 0.279 & $1<3<2$ \\
Naturalness Gay men & 0.407 & -0.707 & -0.161 & $2<3<1$ \\
$n(\%)$ & 122 & 44 & 116 & \\
& $(43.3 \%)$ & $(15.6 \%)$ & $(41.1 \%)$ & \\
\hline Lesbian women & & & & \\
EB Gender & -0.642 & 1.478 & 0.374 & $1<3<2$ \\
EB Lesbian women & -0.701 & 1.630 & 0.400 & $1<3<2$ \\
Naturalness Lesbian women & 0.522 & -0.635 & -0.588 & $2=3<1$ \\
$n(\%)$ & 104 & 30 & 60 & \\
& $(53.6 \%)$ & $(15.5 \%)$ & $(30.9 \%)$ & \\
\hline
\end{tabular}

Note: Post-hoc comparisons performed by the Tukey HSD test. 
A Gay men

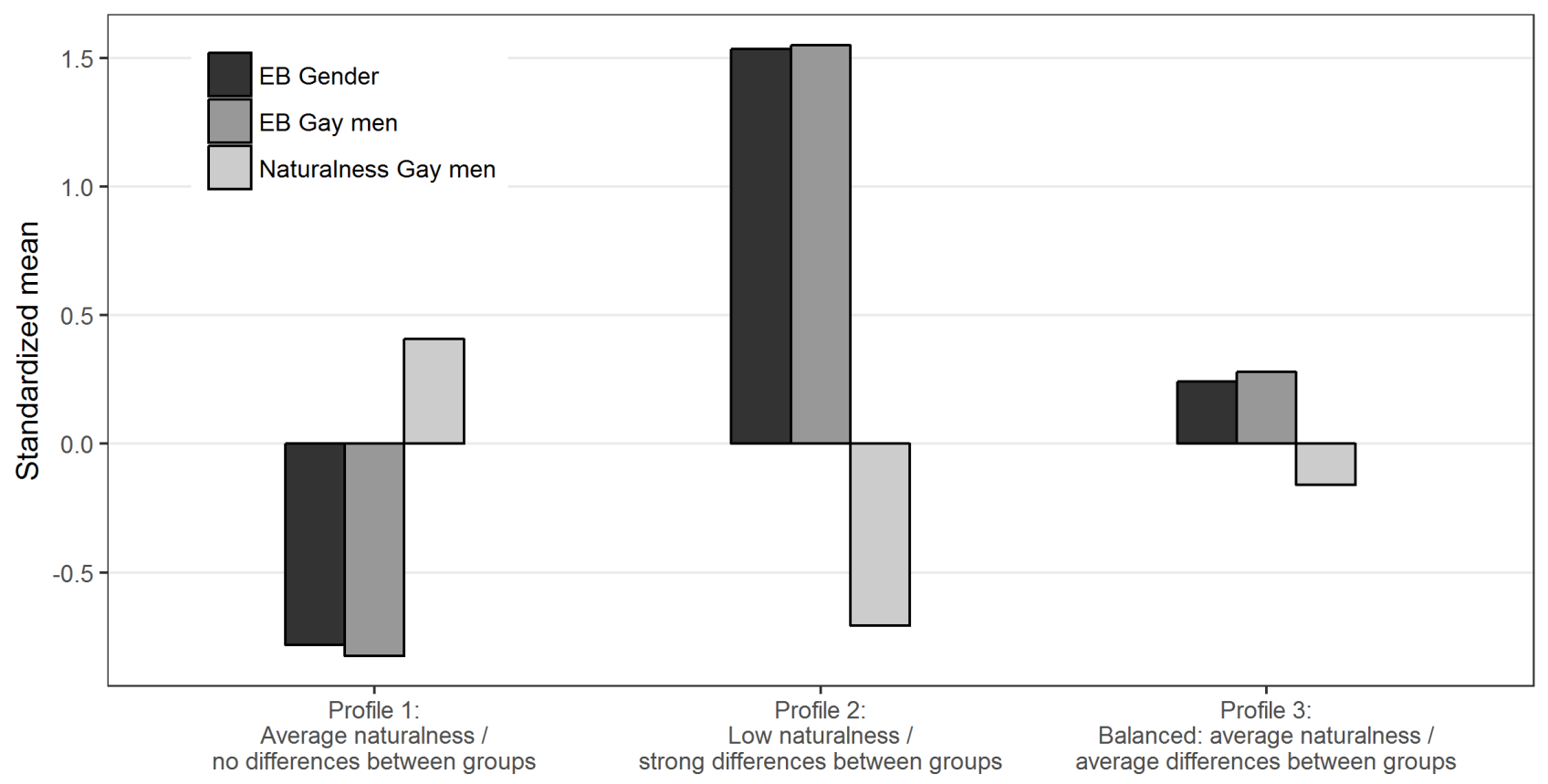

B Lesbian women

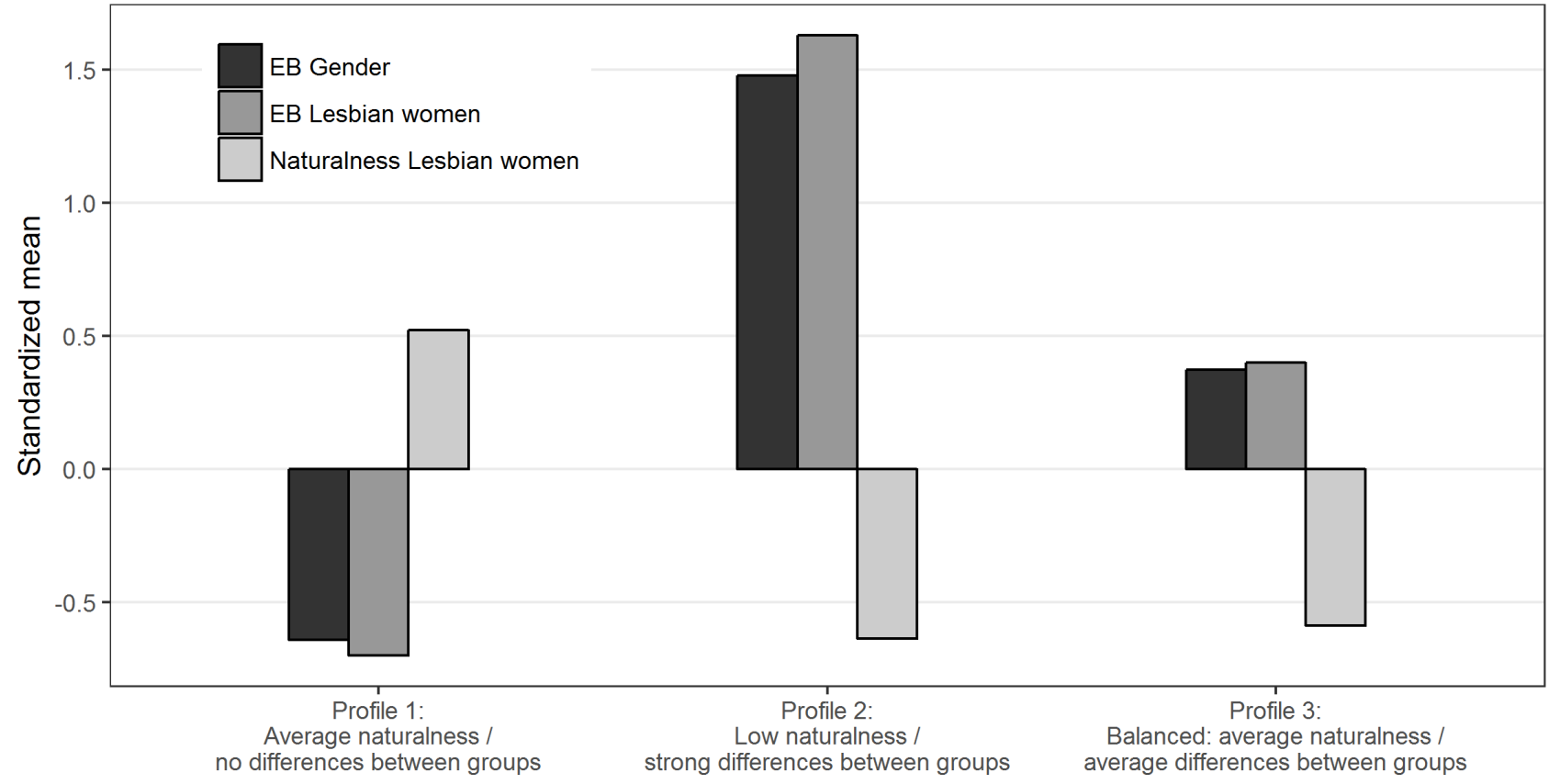

Fig. 1. Characteristics of the three latent profiles for gay men and lesbian women, based on the essentialist beliefs. The results were standardized to facilitate the interpretation. 
As Figure 1 shows, three identical profiles were identified in both cases (for gay men and for lesbian women).

Profile 1 is described as 'Average naturalness - no differences between groups' (gay men: 122 respondents; lesbian women: 104 respondents). Typically, members of this profile have average beliefs about the nature of sexual orientation and do not believe that individuals from different gender groups and sexual orientations have any essential characteristics that distinguish them from each other (scores were more than half of the standard deviation below the mean for essentialist beliefs related to gender and sexual orientation). In other words, these individuals are less likely than others to share the stereotypes related to gender roles and sexual behavior. The individuals with all types of sexual orientation, except homosexual orientation, are represented in Profile 1 in an equivalent way (around $30 \%$ for each group). Individuals with homosexual orientation are underrepresented in Profile 1 (less than $10 \%$ of respondents). The respondents from this profile demonstrated the lowest level of gender identification and RWA compared with people from the other profiles (see Table 5 and Figure 2).

Profile 2 is described as 'Low naturalness - strong differences between groups' (gay men: 44 respondents; lesbian women: 30 respondents). These respondents believe that gay men and lesbian women have some essential characteristics that distinguish them from heterosexuals, and that people from different gender groups are distinguished from each other (more than 1.5 standard deviation for relevant beliefs). They also demonstrate a low level of belief in the naturalness of sexual orientation, 
which means they mostly believe that gay men and lesbian women have chosen their orientation (more than half of the standard deviation). This profile maximally corresponds to heteronormativity attitudes, because these individuals deny the innate nature of sexual orientation and strictly support the gender beliefs system, emphasizing the differences between men and women. The respondents from this profile mainly identified themselves as heterosexual (60\% of respondents in the case of gay men and $58 \%$ of respondents in the case of lesbian women). The individuals with homosexual, bisexual and other non-heterosexual identity are represented in the profile in an equivalent way to each other (around 15\% for each group). The respondents with 'low naturalness - strong differences between groups' beliefs demonstrated the highest level of gender identification and RWA compared with people from the other profiles, as shown in Table 5 and Figure 2.

Profile 3 is described as 'Balanced: average naturalness - average differences between groups' (gay men: 116 respondents; lesbian women: 60 respondents). For these individuals, belief in the naturalness of sexual orientation and essentialist beliefs related to gender and sexual orientation are not distinguished from the average. These respondents demonstrate a balanced view on gender and sexual orientation essentialism. They can combine both beliefs: something in the behavior of nonheterosexuals is an innate characteristic, and something corresponds to social stereotypes relating to gender roles and sexual behavior. In the case of gay men, the individuals with heterosexual, bisexual and other sexual identifications are represented in an equivalent way in this profile. But in the case of lesbian women, the respondents 
mainly identified themselves as heterosexual, similar to respondents in Profile 2 (43\%), while bisexuals and individuals with another sexual identity represent $32 \%$ and $21 \%$, respectively. The respondents had an average level of gender identification and low levels of RWA, similar to the respondents from Profile 1 (see Table 5 and Figure 2).

Additionally, our results suggest that there are no differences in profile membership by age, gender and SDO in both cases.

Table 5. Characteristics of the three essentialist beliefs profiles on the covariates

\begin{tabular}{lllll}
\hline Covariates & Profile 1 & Profile 2 & Profile 3 & $\begin{array}{l}\text { Summary of } \\
\text { significance tests }\end{array}$ \\
& & & & \\
\hline $\begin{array}{l}\text { Gay men } \\
\text { Gender (\% female) }\end{array}$ & 0.893 & 0.730 & 0.820 & $1=2=3$ \\
Age & 20.128 & 20.361 & 20.566 & $1=2=3$ \\
$\begin{array}{l}\text { Sexual orientation } \\
\quad \% \text { heterosexuals }\end{array}$ & & & & \\
$\quad \%$ bisexuals & 0.256 & 0.600 & 0.370 & $1=3<2$ \\
$\quad \%$ others & 0.371 & 0.156 & 0.320 & $2<1=3$ \\
RWA & 0.313 & 0.099 & 0.256 & $2<1=3$ \\
SDO & 2.095 & 3.655 & 2.505 & $1=3<2$ \\
Gender identification & 1.570 & 1.952 & 1.862 & $1=2=3$ \\
Social distance (Gay men) & 3.909 & 4.987 & 4.232 & $1<3<2$ \\
\hline Lesbian women & 1.631 & 2.724 & 1.715 & $1=3<2$ \\
Gender (\% female) & & & & \\
Age & 0.864 & 0.772 & 0.754 & $1=2=3$ \\
Sexual orientation & 20.802 & 21.159 & 20.907 & $1=2=3$ \\
$\quad \%$ heterosexuals & & & & \\
$\quad \%$ bisexuals & 0.310 & 0.577 & 0.431 & $2=3 ; 1=3 ; 1<2$ \\
$\quad \%$ others & 0.338 & 0.171 & 0.317 & $1=2=3$ \\
RWA & 0.283 & 0.113 & 0.209 & $2<1 ; 2=3 ; 1=3$ \\
SDO & 2.069 & 3.615 & 2.699 & $1=3<2$ \\
Gender identification & 1.699 & 1.774 & 2.007 & $1=2=3$ \\
Social distance (Lesbian women) & 3.936 & 4.908 & 4.441 & $1<3<2$ \\
\hline
\end{tabular}

Note: Differences between profiles were tested by the Wald chi-square $\left(\chi^{2}\right)$ tests of mean equality of the auxiliary analyses of covariates. RWA - Right-wing authoritarianism, SDO - Social dominance orientation. 
A Gay men

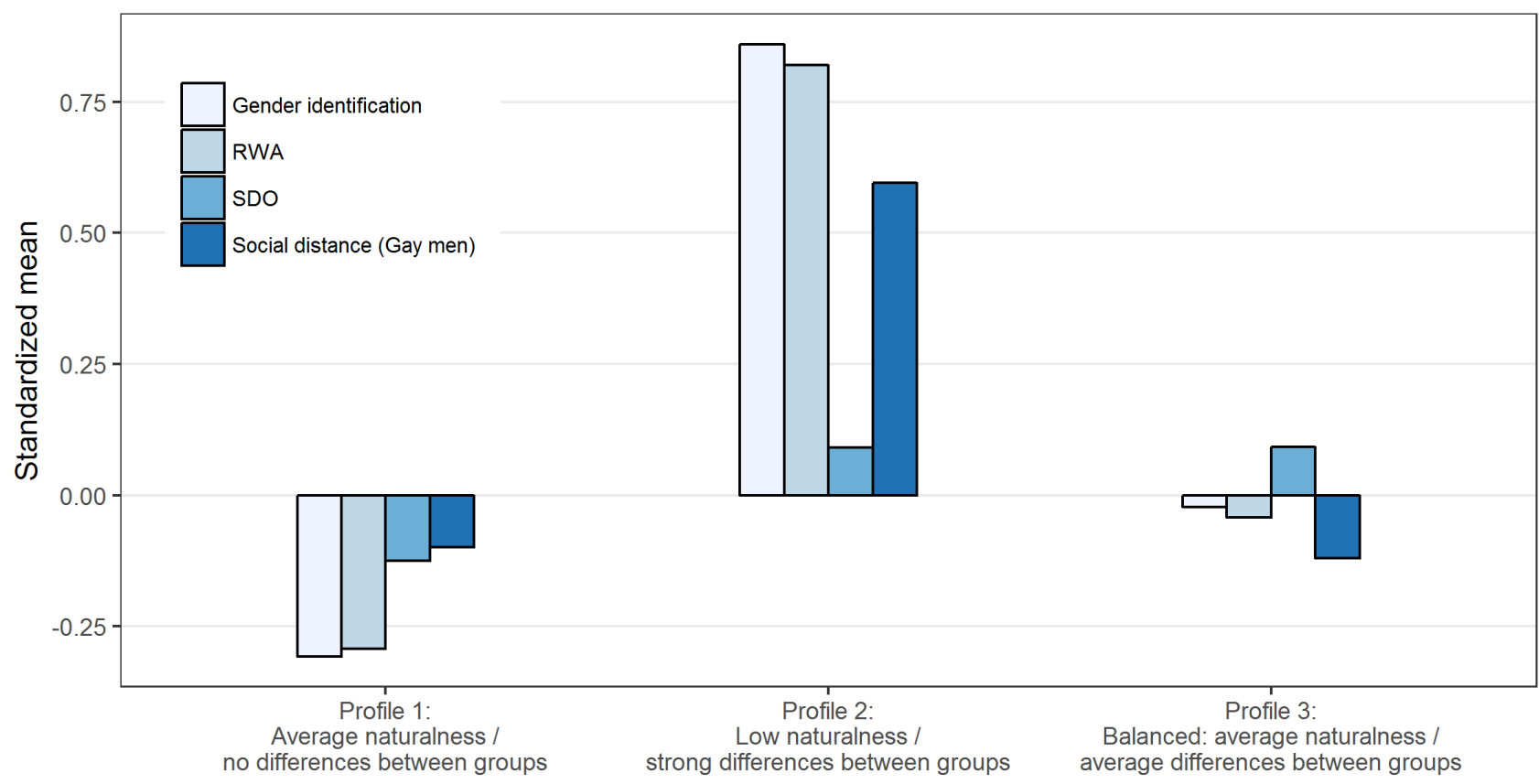

B Lesbian women

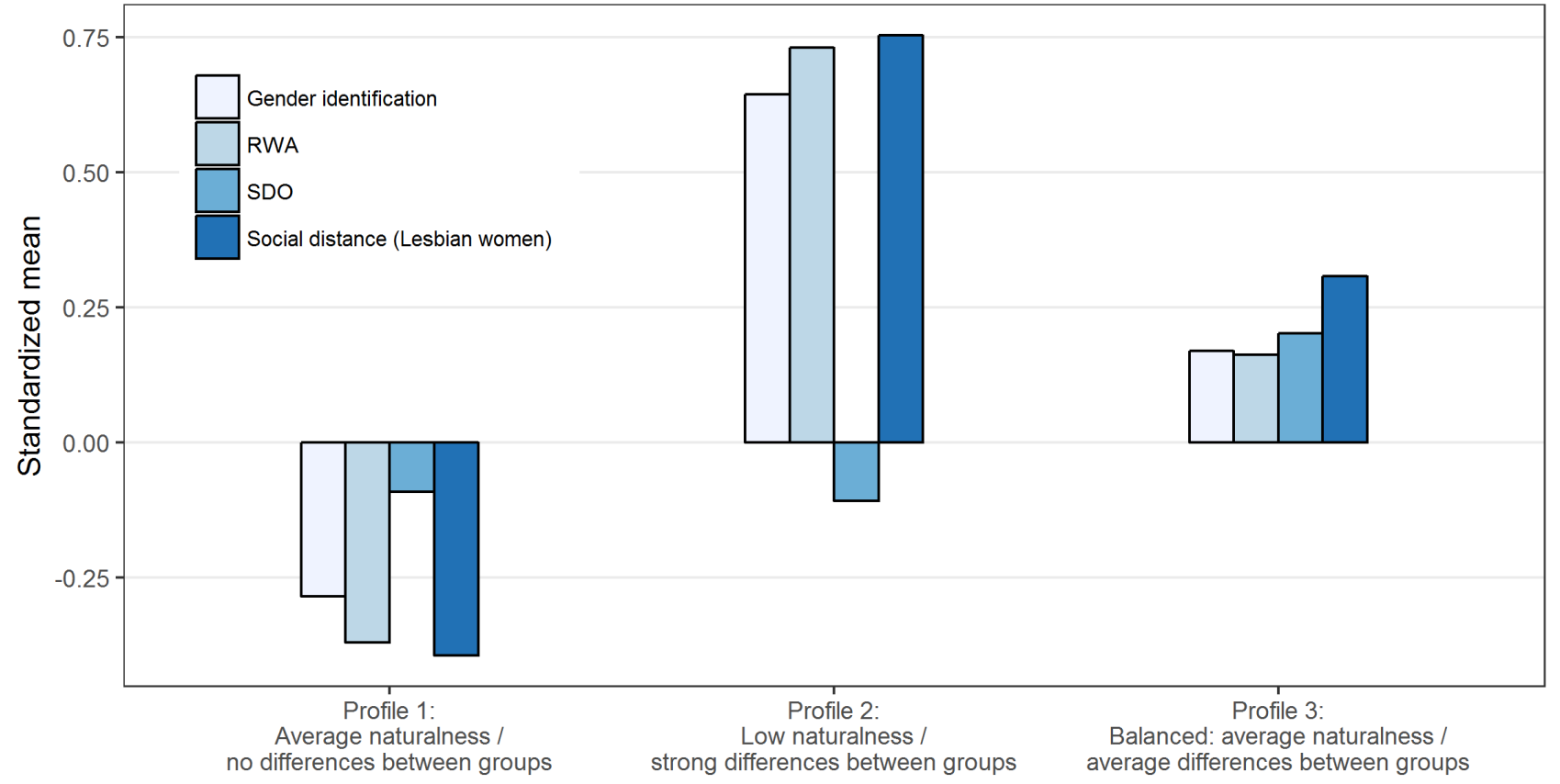

Fig. 2. Characteristics of the latent profiles on the covariates. The results were standardized to facilitate the interpretation. 


\section{Essentialist beliefs profiles and social distance}

The results (shown in Table 5 and Figure 2) indicated significant differences in social distance among the profiles. The greatest desire to maintain a social distance from gay men is demonstrated by the respondents from Profile 2, who believe that there are social or psychological differences between homosexual and heterosexual men and women, and that sexual orientation is based on an individual's free choice. The level of social distance from lesbian women does not differ between respondents from Profile 2 and Profile 3, while Profile 2 shows the highest absolute level of social distance. In the cases of both gay men and lesbian women, the lowest levels of social distance are demonstrated by the individuals in Profile 1 .

\section{Discussion}

This study was designed to investigate the coexistence of different essentialist beliefs related to sexual orientation and gender in Russia, using a person-centered approach. This approach took into account the existence of subgroups in society sharing different combinations of essentialist beliefs. We aimed to understand whether individuals with various combinations of essentialist beliefs differed in their social distance from gay men and lesbian women.

Our results demonstrated that distinct essentialist belief profiles could be identified. In both cases (for gay men and lesbian women), the solution included the same set of three profiles which are partially similar to the profiles from the studies by Grzanka, Zeiders, and Miles (2016). We demonstrated the validity of different 
essentialist belief profiles by showing significant differences in the levels of identification with gender group and RWA across profiles. The first profile ('Average naturalness - no differences between groups') included predominantly nonheterosexuals (homosexuals, bisexuals and other orientation); $74 \%$ and $69 \%$ of respondents rated the profiles about gay men and lesbian women, respectively. The second profile ('Low naturalness - strong differences between groups') predominantly consisted of respondents who identified themselves as heterosexuals $(60 \%$ and $58 \%$ respondents rated the profiles about gay men and lesbian women, respectively) and could be characterized as having heteronormative attitudes towards non-heterosexuals. These results agree with previous findings that heterosexuals often consider sexual orientation to be a free choice and perceive non-heterosexuals (gay men and lesbian women) as a threat to their values; as a result, they emphasize differences in the essential characteristics of gay men, lesbian women and heterosexuals (FalomirPichastor \& Mugny, 2009). Non-heterosexuals, however, are more likely to perceive sexual orientation as a biological phenomenon, and as a result belong to a profile with a high or average level of naturalness belief, and they do not emphasize fundamental differences from heterosexuals (Grzanka et al., 2016). The third, 'Balanced' profile included predominantly non-heterosexual (homosexuals, bisexuals and other) respondents from the sample who did not demonstrate certain stereotypes related to gender and sexual orientation; $63 \%$ and $57 \%$ of respondents rated the profiles about gay men and lesbian women, respectively. 
Our results suggest that individuals from the different profile groups demonstrate social distance from gay men and lesbian women to varying degrees. First of all, respondents who believe that gay men and lesbian women 'chose to be this way' and that there are strong differences between non-heterosexuals and heterosexuals, and between men and women (Profile 2), demonstrate a higher level of social distance than other individuals. These respondents also demonstrated the highest level of gender identification and RWA compared with people from the other profiles. Despite the fact that the level of RWA is low among all respondents, it is significantly different between profiles. In particular, respondents from Profile 2 demonstrated an average level of RWA compared with other participants who demonstrated a low level of RWA (see Table 5). Based on the characteristics of respondents from Profile 2, it can be assumed that in this profile the level of social distance is determined by a combination of the following factors: heterosexual sexual identity, high gender identity and average authoritarianism. This assumption supports the results obtained in previous research that high identification with gender group relates to high sexual prejudice (Falomir-Pichastor \& Mugny, 2009), that heterosexuals with strong authoritarian attitudes do not accept a biological basis for sexual orientation (Haslam et al., 2002), and that RWA is associated with negative attitudes toward both lesbian women and gay men (Haslam \& Levy, 2006; Whitley, Jr. \& Ægisdóttir, 2000; Whitley \& Lee, 2000). In general, our results suggest that heteronormativity might be supported by identification with gender group and RWA as a strong support for traditional values and norms (Altemeyer, 1998). We assume that RWA is associated 
with greater perceptions of group boundaries because lesbian women and gay men challenge traditional sexual roles; consequently, they are considered as outliers relative to heterosexual women and men, which leads to greater social distance.

We also found that for respondents from Profile 2, the social distance from gay men is greater than the distance from lesbian women. These results seem logical in the context of a gender belief system that suggests that the gender norm is stronger for men than for women, and that men are punished more for behavior that does not correspond to ideas about masculinity. Katz-Wise and Hyde (2012) conducted a metaanalysis that demonstrated that non-heterosexual males experience some types of victimization more often than non-heterosexual females do. In contrast to Profile 2, the respondents from Profile 1 (predominantly non-heterosexuals) showed a minimal level of social distance, and low identification with gender groups and RWA across profiles.

Interestingly, and in contrast to previous findings that SDO tends to correlate positively with prejudice against gay men and lesbian women (Rios, 2013), our results clearly indicate that the level of SDO did not differ across profiles with different social distance. This result might be linked to the low level of SDO across respondents and the survey's Russian social context. Studies have shown that SDO, as a tendency to prefer the hierarchy in intergroup relations (Pratto et al., 1994), predicts negative attitudes only towards groups that advocate political change and have hierarchyattenuating intentions (Crawford, Mallinas, \& Furman, 2015; Crawford \& Pilanski, 2014). According to the Russian laws concerning the prohibition of non-traditional sexual relations among minors, non-heterosexual people cannot openly declare their 
sexual orientation and protect their rights. As a result, they cannot be considered as a significant political force threatening the status and positions of heterosexual people.

Our findings expand the previous results because we identified a complementary robust essentialist belief profile that we labeled 'Balanced' (Profile 3). In the case of gay men, Profile 3 included mainly non-heterosexual respondents who demonstrated a low level of social distance towards gay men. At the same time, in the case of lesbian women this profile included as many heterosexuals as did Profile 2. Moreover, these respondents demonstrated a similar level of social distance from lesbian women to those in Profile 2. This result might be related to the fact our sample included mostly women. In Profile 3, the non-heterosexual women might demonstrate the high level of internalized homonegativity that is defined as 'the gay person's direction of negative social attitudes toward the self' (Meyer \& Dean, 1998, p.161). Morandini, Blaszczynski, Ross, Costa, and Dar-Nimrod (2015) showed that internalized homonegativity was not associated with beliefs in discreteness towards sexual orientation, which is also supported by our data. Besides that, researchers have shown that identity uncertainty is associated with increased levels of internalized homonegativity (Borders, Guillén, \& Meyer, 2014), which is reaffirmed by our findings about the average level of gender identification from respondents in Profile 3. The negative Russian discourse about non-heterosexuals could be internalized as part of the self-image of non-heterosexual individuals, which in turn could lead to a desire to be distanced from other non-heterosexuals. 
The results of our research lead to three important conclusions. First, our study suggests that essentialist thinking is a common pattern of everyday perception: if an individual believes that group membership is based on essential characteristics, s/he will generalize this belief for any social group (e.g., both gender and sexual orientation). Second, we demonstrated the strong relationship between representation about gender and sexual orientation in the individual mind. Schilt and Westbrook, (2009) showed that gender and sexuality are inextricably tied together because people mix the criteria for categorization in the gender or sexual orientation categories. In particular, they include a representation about sexual orientation in the representation about gender and vice versa. In summary, essentialist beliefs about gender and sexual orientation may be at least equally important for understanding sexual prejudice, while beliefs about the biological differences between gay men/lesbian women and heterosexuals may be less crucial and powerful as a predictor of sexual prejudice.

Third, essentialist beliefs about gender and sexual orientation emphasize the boundaries between groups and lead to an increase in social distance. This fact is important for understanding sexual prejudice, because social distance reduces the probability of contact with non-heterosexuals, which in turn reduces the likelihood of reducing sexual prejudices. Studies show that according to intergroup contact theory (Pettigrew \& Tropp, 2006; Smith, Axelton, \& Saucier, 2009), contact with lesbian women and gay men reduces prejudice toward non-heterosexuals (Cunningham \& Melton, 2013; Lytle et al., 2017). Importantly, maintaining social distance increases the likelihood of supporting discriminatory laws and initiatives (Roberts et al., 2017). 
Our study met some limitations that future research should take into account. First, our results may be related to the local cultural context. As we discussed above, homophobia is very common among Russians. As a result, our findings may not apply to another cultural context. Second, the characteristics of our sample could have affected the results. In particular, the perceptions of gay men/lesbian women by men and women and individuals with different sexual orientations might differ. So, the dominance of women in the sample could have influenced our findings. Grzanka and colleagues (2016) have shown that for women compared with men, negative attitudes towards non-heterosexuals are connected with strong beliefs in discreteness, homogeneity and informativeness of sexual orientation, and a low belief in naturalness. In addition, women have lower levels of sexual prejudice than men (Herek, 2000).

A third limitation involves the method of recruiting participants via different LGBT and heterosexual communities in social networks, which could have led to a larger proportion of non-heterosexual participants (homosexuals, bisexual, and other orientation) in the sample, because heterosexuals often started, but did not finish, filling out our questionnaire. This may be due to the fact that the topic of research was unpleasant for them and because of negative discourse about homosexuality in Russia (Kondakov, 2014; Novitskaya, 2017; Wilkinson, 2014). Meanwhile, homosexuals, bisexuals, and other non-heterosexual individuals may have seen this questionnaire as a way to speak out about their sexuality and confirm their identity, which may have led to a greater completion rate. The large number of non-heterosexual participants may 
have affected our findings, in particular because of the level of internalized homonegativity. Unfortunately, our study did not control for this factor and in subsequent studies it would be important to take it into account.

\section{References}

Agadullina, E. R., \& Chumakova, M. (2017). Psychological Essentialism:

Development and Adaptation the Scale. Social Psychology and Society, 3, 147162. https://doi.org/10.17759/sps.20170803011

Altemeyer, B. (1998). The Other “Authoritarian Personality.” Advances in Experimental Social Psychology, 30, 47-92.

Altemeyer, B. (2006). The Authoritarians. Retrieved from http://members.shaw.ca/jeanaltemeyer/drbob/TheAuthoritarians.pdf

Arseneau, J. R., Grzanka, P. R., Miles, J. R., \& Fassinger, R. E. (2013). Development and initial validation of The Sexual Orientation Beliefs Scale (SOBS). Journal of Counseling Psychology, 60(3), 407-20. https://doi.org/10.1037/a0032799

Bastian, B., \& Haslam, N. (2006). Psychological essentialism and stereotype endorsement. Journal of Experimental Social Psychology, 42(2), 228-235. https://doi.org/10.1016/j.jesp.2005.03.003

Borders, A., Guillén, L., \& Meyer, I. H. (2014). Rumination, Sexual Orientation Uncertainty, and Psychological Distress in Sexual Minority University Students. The Counseling Psychologist, 42(4), 497-523. https://doi.org/10.1177/0011000014527002 
Brickman, D. W. (2009). The Implications of Essentialist Beliefs for Prejudice. The University of Michigan.

Crawford, J. T., Mallinas, S. R., \& Furman, B. J. (2015). The Balanced Ideological Antipathy Model. Personality and Social Psychology Bulletin, 41(12), 1607-1622. https://doi.org/10.1177/0146167215603713

Crawford, J. T., \& Pilanski, J. M. (2014). The Differential Effects of Right-Wing Authoritarianism and Social Dominance Orientation on Political Intolerance. Political Psychology, 35(4), 557-576. https://doi.org/10.1111/pops.12066

Cunningham, G. B., \& Melton, E. N. (2013). The Moderating Effects of Contact with Lesbian and Gay Friends on the Relationships Among Religious Fundamentalism, Sexism, and Sexual Prejudice. Journal of Sex Research, 50(3-4), 401-408. https://doi.org/10.1080/00224499.2011.648029

Esses, V. M., \& Dovidio, J. F. (2002). The Role of Emotions in Determining Willingness to Engage in Intergroup Contact. Personality and Social Psychology Bulletin, 28(9), 1202-1214. https://doi.org/10.1177/01461672022812006 Falomir-Pichastor, J. M., \& Hegarty, P. (2014). Maintaining Distinctions Under Threat: Heterosexual Men Endorse the Biological Theory of Sexuality When Equality is the Norm. British Journal of Social Psychology, 53(4), 731-751. https://doi.org/10.1111/bjso.12051

Falomir-Pichastor, J. M., \& Mugny, G. (2009). “I'm not gay. . . . I'm a real man!”: Heterosexual Men's Gender Self-Esteem and Sexual Prejudice. Personality and Social Psychology Bulletin, 35(9), 1233-1243. 
https://doi.org/10.1177/0146167209338072

Grzanka, P. R., Zeiders, K. H., \& Miles, J. R. (2016). Beyond “ Born This Way ?” Reconsidering Sexual Orientation Beliefs and Attitudes. Journal of Counseling Psychology, 63(1), 67-75. https://doi.org/10.1037/cou0000124

Gulevich, O. A. (2017). Psychology of intergroup relations. Moscow: U-rait.

Gulevich, O. A., Osin, E. N., Isaenko, N. A., \& Brainis, L. M. (2016). Attitudes To Homosexuals in Russia: Content, Structure, and Predictors. Psychology. Journal of the Higher School of Economics., 13(1), 79-110.

Gulevich, O. A., Osin, E. N., Isaenko, N. A., \& Brainis, L. M. (2017). Scrutinizing Homophobia: A Model of Perception of Homosexuals in Russia. Journal of Homosexuality, 00918369.2017.1391017. https://doi.org/10.1080/00918369.2017.1391017

Haslam, N., \& Levy, S. R. (2006). Essentialist Beliefs about Homosexuality: Structure and Implications for Prejudice. Personality and Social Psychology Bulletin, 32(4), 471-485. https://doi.org/10.1177/0146167205276516

Haslam, N., Rothschild, L., \& Ernst, D. (2000). Essentialist Beliefs About Social Categories. British Journal of Social Psychology, 39(1), 113-127. https://doi.org/10.1348/014466600164363

Haslam, N., Rothschild, L., \& Ernst, D. (2002). Are Essentialist Beliefs Associated with Prejudice? British Journal of Social Psychology, 41, 87-100. https://doi.org/10.1348/014466602165072

Hegarty, P. (2002). 'It"s Not a Choice, it's the Way we're Built': Symbolic Beliefs 
about Sexual Orientation in the US and Britain. Journal of Community and Applied Social Psychology, 12(3), 153-166. https://doi.org/10.1002/casp.669 Hegarty, P., \& Pratto, F. (2004). The Differences That Norms Make: Empiricism, Social Constructionism, and the Interpretation of Group Differences. Sex Roles, 50(7/8), 2004. https://doi.org/10.1023/B:SERS.0000023065.56633.cb

Herek, G. M. (2000). The Psychology of Sexual Prejudice. Current Directions in Psychological Science, 9(1), 19-22.

Horvath, M., \& Ryan, A. M. (2003). Antecedents and Potential Moderators of the Relationship Between Attitudes and Hiring Discrimination on the Basis of Sexual Orientation. Sex Roles, 48(3-4), 115-130. https://doi.org/10.1023/A:1022499121222

Hubbard, K., \& de Visser, R. O. (2015). Not Just Bi the Bi: The Relationship between Essentialist Beliefs and Attitudes about Bisexuality. Psychology \& Sexuality, 6(3), 258-274. https://doi.org/10.1080/19419899.2014.987682

Human Rights Watch. Russia: Sochi games highlight homophobic violence:

Authorities turn blind eye to crimes against LGBT people. (2014). Retrieved from http://www.hrw.org/news/2014/02/03/russia-sochi-games-highlight-homophobicviolence

Ingraham, C. (1994). The Heterosexual Imaginary: Feminist Sociology and Theories of Gender. Sociological Theory, 12(2), 203-219. https://doi.org/10.2307/201865

Jayaratne, T. E., Ybarra, O., Sheldon, J. P., Brown, T. N., Feldbaum, M., Pfeffer, C. a., \& Petty, E. M. (2006). White Americans' Genetic Lay Theories of Race 
Differences and Sexual Orientation: Their Relationship with Prejudice toward Blacks, and Gay Men and Lesbians. Group Processes \& Intergroup Relations, 9(1), 77-94. https://doi.org/10.1177/1368430206059863

Jost, J. T., Banaji, M. R., \& Nosek, B. A. (2004). A Decade of System Justification Theory: Accumulated Evidence of Conscious and Unconscious Bolstering of the Status Quo John. Political Psychology, 25(6), 881-919. https://doi.org/10.1111/j.1467-9221.2004.00402.x

Katz-Wise, S. L., \& Hyde, J. S. (2012). Victimization Experiences of Lesbian, Gay, and Bisexual Individuals: A Meta-Analysis. Journal of Sex Research, 49(2-3), 142-167. https://doi.org/10.1080/00224499.2011.637247

Keller, J. (2005). In Genes We Trust: The Biological Component of Psychological Essentialism and Its Relationship to Mechanisms of Motivated Social Cognition. Journal of Personality and Social Psychology, 88(4), 686-702. https://doi.org/10.1037/0022-3514.88.4.686

Kite, M. E., \& Deaux, K. (1987). Gender Belief Systems: Homosexuality and the Implicit Inversion Theory. Psychology of Women Quarterly, 11(1), 83-96. https://doi.org/10.1111/j.1471-6402.1987.tb00776.x

Kondakov, A. (2014). The Silenced Citizens of Russia: Exclusion of Non-heterosexual Subjects From Rights-Based Citizenship. Social and Legal Studies, 23(2), 151174. https://doi.org/10.1177/0964663913505315

Leach, C. W., van Zomeren, M., Zebel, S., Vliek, M. L. W., Pennekamp, S. F., Doosje, B., ... Spears, R. (2008). Group-level self-definition and self-investment: A 
hierarchical (multicomponent) model of in-group identification. Journal of Personality and Social Psychology, 95(1), 144-165. https://doi.org/10.1037/00223514.95.1.144

Levy, S. R., Chiu, C., \& Hong, Y. (2006). Lay Theories and Intergroup Relations. Group Processes and Intergroup Relations, 9(1), 5-24. https://doi.org/10.1177/1368430206059855

Lovakov, A. V, Agadullina, E. R., \& Osin, E. N. (2015). A Hierarchical (Multicomponent) Model of In-Group Identification: Examining in Russian Samples. The Spanish Journal of Psychology, 18. https://doi.org/10.1017/sjp.2015.37

Lytle, A., Dyar, C., Levy, S. R., \& London, B. (2017). Essentialist Beliefs:

Understanding Contact with and Attitudes towards Lesbian and Gay Individuals. British Journal of Social Psychology, 56(1), 64-88. https://doi.org/10.1111/bjso.12154

Magidson, J., \& Vermunt, J. K. (2002). Latent Class Models for Clustering: A Comparison with K-means. Canadian Journal of Marketing Research, 20, 36-43. Marsh, H. W., Lüdtke, O., Trautwein, U., \& Morin, A. J. S. (2009). Classical Latent Profile Analysis of Academic Self-Concept Dimensions: Synergy of Person- and Variable-Centered Approaches to Theoretical Models of Self-Concept. Structural Equation Modeling: A Multidisciplinary Journal, 16(2), 191-225. https://doi.org/10.1080/10705510902751010

McCutcheon, J., \& Morrison, M. A. (2015). The Effect of Parental Gender Roles on 
Students' Attitudes Toward Lesbian, Gay, and Heterosexual Adoptive Couples. Adoption Quarterly, 18(2), 138-167.

https://doi.org/10.1080/10926755.2014.945702

McLachlan, G., \& Peel, D. (2000). Finite mixture models. New York: Wiley.

Meyer, I. H., \& Dean, L. (1998). Internalized Homophobia, Intimacy, and Sexual

Behavior among Gay and Bisexual Men. In Stigma and Sexual Orientation:

Understanding Prejudice against Lesbians, Gay Men, and Bisexuals (pp. 160-

186). 2455 Teller Road, Thousand Oaks California 91320 United States: SAGE

Publications, Inc. https://doi.org/10.4135/9781452243818.n8

Morandini, J., Blaszczynski, A., Ross, M., Costa, D., \& Dar-Nimrod, I. (2015).

Essentialist Beliefs, Sexual Identity Uncertainty, Internalized Homonegativity and Psychological Wellbeing in Gay Men. Journal of Counseling Psychology, 62(3), 413-424. https://doi.org/10.1037/cou0000072

Morin, A. J. S., Morizot, J., Boudrias, J.-S., \& Madore, I. (2011). A Multifoci PersonCentered Perspective on Workplace Affective Commitment: A Latent Profile/Factor Mixture Analysis. Organizational Research Methods, 14(1), 58-90. https://doi.org/10.1177/1094428109356476

Morrison, M. A., \& Morrison, T. G. (2003). Development and Validation of a Scale Measuring Modern Prejudice Toward Gay Men and Lesbian Women. Journal of Homosexuality, 43(2), 15-37. https://doi.org/10.1300/J082v43n02

Morton, T. A., Postmes, T., Haslam, S. A., \& Hornsey, M. J. (2009). Theorizing Gender in the Face of Social Change: Is there Anything Essential about 
Essentialism? Journal of Personality and Social Psychology, 96(3), 653-664. https://doi.org/10.1037/a0012966

Muraco, A. (2005). Heterosexual Evaluations of Hypothetical Friendship Behavior Based on Sex and Sexual Orientation. Journal of Social and Personal Relationships, 22(5), 587-605. https://doi.org/10.1177/0265407505054525

Novitskaya, A. (2017). Patriotism, Sentiment, and Male Hysteria: Putin's Masculinity Politics and the Persecution of Non-heterosexual Russians. NORMA, 12(3-4), 302-318. https://doi.org/10.1080/18902138.2017.1312957

Nürnberger, M., Nerb, J., Schmitz, F., Keller, J., \& Sütterlin, S. (2015). Implicit Gender Stereotypes and Essentialist Beliefs Predict Preservice Teachers' Tracking Recommendations. The Journal of Experimental Education, 84(1), 152-174. https://doi.org/10.1080/00220973.2015.1027807

Nylund, K. L., Asparouhov, T., \& Muthén, B. O. (2007). Deciding on the Number of Classes in Latent Class Analysis and Growth Mixture Modeling: A Monte Carlo Simulation Study. Structural Equation Modeling: A Multidisciplinary Journal, 14(4), 535-569. https://doi.org/10.1080/10705510701575396

O’Dwyer, C. (2013). Gay Rights and Political Homophobia in Postcommunist Europe: Is there an "EU effect”? In M. L. Weiss \& M. J. Bosia (Eds.), Global homophobia: States, movements, and the politics of oppression (pp. 103-126). Champaign, IL: University of Illinois Press.

Pettigrew, T. F., \& Tropp, L. R. (2006). A Meta-analytic Test of Intergroup Contact Theory. Journal of Personality and Social Psychology, 90(5), 751-783. 
https://doi.org/10.1037/0022-3514.90.5.751

Phoenix, A., Frosh, S., \& Pattman, R. (2003). Producing Contradictory Masculine Subject Positions: Narratives of Threat, Homophobia and Bullying in 11-14 Year Old Boys. Journal of Social Issues, 59(1), 179-195. https://doi.org/10.1111/15404560.t01-1-00011

Pipiya, K. (2015). “Nevidimoe men'shinstvo”: K probleme gomofobii v Rossii ["An unseen minority”: The problem of homophobia in Russia]. Moscow, Russia: Levada-Centre. Retrieved from http://www.levada.ru/2015/05/05/nevidimoemenshinstvo-k-problemegomofobii-v-rossii/

Pratto, F., Sidanius, J., Stallworth, L. M., \& Malle, B. F. (1994). Social Dominance Orientation: A Personality Variable Predicting Social and Political Attitudes. Journal of Personality and Social Psychology, 67(4), 741-763. https://doi.org/10.1037/0022-3514.67.4.741

Prentice, D. A., \& Miller, D. T. (2006). Essentializing Differences Between Women and Men. Psychological Science, 17(2), 129-135. https://doi.org/10.1111/j.14679280.2006.01675.x

Prentice, D. A., \& Miller, D. T. (2007). Psychological Essentialism of Human Categories. Current Directions in Psychological Science, 16(4), 202-206. https://doi.org/10.1111/j.1467-8721.2007.00504.x

Reyna, C., Wetherell, G., Yantis, C., \& Brandt, M. J. (2014). Attributions for Sexual Orientation vs. Stereotypes: How Beliefs about Value Violations Account for Attribution Effects on Anti-gay Discrimination. Journal of Applied Social 
Psychology, 44(4), 289-302. https://doi.org/10.1111/jasp.12226

Rios, K. (2013). Right-wing Authoritarianism Predicts Prejudice against

"Homosexuals" but not "Gay Men and Lesbians." Journal of Experimental Social Psychology, 49(6), 1177-1183. https://doi.org/10.1016/j.jesp.2013.05.013

Roberts, S. O., Ho, A. K., Rhodes, M., \& Gelman, S. A. (2017). Making Boundaries

Great Again: Essentialism and Support for Boundary-Enhancing Initiatives.

Personality and Social Psychology Bulletin, 14616721772480.

https://doi.org/10.1177/0146167217724801

Rowatt, W. C., LaBouff, J., Johnson, M., Froese, P., \& Tsang, J. (2009). Associations among Religiousness, Social Attitudes, and Prejudice in a National Random Sample of American Adults. Psychology of Religion and Spirituality, 1(1), 14-24. https://doi.org/10.1037/a0014989

Schilt, K., \& Westbrook, L. (2009). Doing Gender, Doing Heteronormativity. Gender \& Society, 23(4), 440-464. https://doi.org/10.1177/0891243209340034

Schwarz, G. (1978). Estimating the dDimension of a Model. The Annals of Statistics, $6(2), 461-464$.

Smiler, A. P., Gelman, S. A., Schomerus, G., Matschinger, H., \& Angermeyer, M. C. (2014). Determinants of gender essentialism in college students. Psychological Medicine, 44(11-12), 303-14. https://doi.org/10.1007/s11199-008-9402-x

Smith, S. J., Axelton, A. M., \& Saucier, D. A. (2009). The Effects of Contact on Sexual Prejudice: A Meta-Analysis. Sex Roles, 61(3-4), 178-191. https://doi.org/10.1007/s11199-009-9627-3 
Soboleva, I. V., \& Bakhmetjev, Y. A. (2015). Political Awareness and Self-Blame in the Explanatory Narratives of LGBT People Amid the Anti-LGBT Campaign in Russia. Sexuality and Culture, 19(2), 275-296. https://doi.org/10.1007/s12119$014-9268-8$

Whitley, Jr., B. E., \& Ægisdóttir, S. (2000). The Gender Belief System, Authoritarianism, Social Dominance Orientation, and Heterosexuals' Attitude toward Lesbians and Gay Men. Sex Roles, 42(11/12), 947-967. https://doi.org/10.1023/A:1007026016001

Whitley, B. E., \& Lee, S. E. (2000). The Relationship of Authoritarianism and Related Constructs to Attitudes Toward Homosexuality. Journal of Applied Social Psychology, 30(1), 144-170. https://doi.org/10.1111/j.1559-1816.2000.tb02309.x Wilkinson, C. (2014). Putting "Traditional Values" Into Practice: The Rise and Contestation of Anti-Homopropaganda Laws in Russia. Journal of Human Rights, 13(3), 363-379. https://doi.org/10.1080/14754835.2014.919218

Williams, M. J., \& Eberhardt, J. L. (2008). Biological Conceptions of Race and the Motivation to Cross Racial Boundaries. Journal of Personality and Social Psychology, 94(6), 1033-1047. https://doi.org/10.1037/0022-3514.94.6.1033

Zagefka, H., Nigbur, D., Gonzalez, R., \& Tip, L. (2013). Why does Ingroup Essentialism Increase Prejudice against Minority Members? International Journal of Psychology, 48(1), 60-68. https://doi.org/10.1080/00207594.2012.729841 